\title{
Smart Parking System based on IOT
}

\author{
Hardik Tanti ${ }^{1}$, Pratik Kasodariya ${ }^{2}$, Shikha Patel ${ }^{3}$, Dhaval H. Rangrej ${ }^{4}$ \\ ${ }^{4}$ Assistant Professor Laxmi Institute Of Technology, Sarigam \\ 1,2,3 Laxmi Institute Of Technology, Sarigam
}

\begin{abstract}
Today many metropolitan areas have seen explosive growth in the number of visitors and patrons due to urban revitalization, extension of transit services into suburban areas, and the general trend toward increased mobility of our society. As a result, there are too many vehicles on the road and insufficient parking spaces. This has led to the need for an efficient parking management system. With the help of a computerized system we can deliver a good service to citizens who wants to park their vehicle into the any organization's premises using Internet of Things (IOT) based on parking management system. In this context, Internet of Things (IOT) uses sensors to connect physical parking space infrastructures with information and communication technologies, where cloud-based smart management services are provided. To implement this concept a mobile based application would be developed. This mobile application will allow an end user to check the availability of parking space and book a particular parking lot accordingly. Each parking lot would be equipped with a control system that enables monitoring of the number of free and occupied parking places and informing users about the parking lot status (open with/without free available parking spaces or closed) Additionally the application would display parking service payment according to parking time duration. Also it will sense if a vehicle has arrived on the gate for automated gate opening. This allows users to check for available parking space online from anywhere for hassle free parking. Thus, the system solves the parking issue.
\end{abstract}

Keywords- Smart Parking, Internet of Things, Mobile Application, Show available parking lots as per location, Time Duration, Online Payment.

\section{INTRODUCTION}

Due to the proliferation in the number of vehicles on the road, traffic problems are bound to exist. This is due to the fact that the current transportation infrastructure and car park facility developed are unable to cope with the influx of vehicles on the road. To alleviate the aforementioned problems, the smart parking system has been developed. With the implementation of the smart parking system, patrons can easily locate and secure a vacant parking space at any car park deemed convenient to them. Vehicle ingress and egress are also made more convenient with the implementation of hassle free

payment mechanism. With the help of a computerized system we can deliver a good service to citizens who want to park their vehicle into the any organization's premises using Internet of Things (IOT) based on parking management system. In this context, Internet of Things (IOT) uses sensors to connect physical parking space infrastructures with information and communication technologies, where cloud-based smart management services are provided. To implement this concept a mobile based application would be developed. This mobile application will allow an end user to check the availability of parking space and book a particular parking lot accordingly. Each parking lot would be equipped with a control system that enables monitoring of the number of free and occupied parking places and informing users about the parking lot status (open with/without free available parking spaces or closed) Additionally the application would display parking service payment according to parking time duration. Also it will sense if a vehicle has arrived on the gate for automated gate opening. This allows users to check for available parking space online from anywhere for hassle free parking. Thus, the system solves the parking issue.

\section{LITERATURE SURVEY}

Aditya Basu [1] says that, Smart Parking systems typically obtains information about available parking spaces in a particular geographic area and process is real-time to place vehicles at available positions. It involves using low-cost sensors, real-time data collection, and mobile-phone enabled automated payment systems that allow people to reserve parking in advance or very accurately predict where they will likely find a spot. When deployed as a system, smart parking thus reduces car emissions in urban centers by reducing the need for people to needlessly circle city blocks searching for parking. It also permits cities to carefully manage their parking supply Smart parking helps one of the biggest problems on driving in urban areas; finding empty parking spaces and controlling illegal parking. This implies M2M technologies aims rightness/safety as well as convenience. The Parking Assistance System includes three modules-Monitoring modules, Control module and a displaying unit. Along with above three modules it will also have centralized supervisory system to maintain a data base of parking space and will have a SMS gateway. The monitoring module includes ultrasonic sensors/ ambient light sensor which identifies the free parking spaces and transmits the Information to control unit through ZigBee. Apart from detecting the car the sensor also provides additional information like the stretch of time the car has been parked and also its health status. The control units process the information and send the information to Centralized supervisory system. Centralized supervisory system receives information of parking space from the controller through UDP. It then sends the information such as slot allotted, time parked, billing information and directional details to the user's mobile phone.

Limitation: The limitation of this paper is that it does not include payment system, so it is not applicable for payable parking.

Anusooya G, Christy Jackson J, Sathyarajasekaran K and Kumar Kannan [2] says that, the main objective is to avoid the cramming in the car parking area by implementing an efficient car parking system along with a user-friendly application for an ease of use. Normally at public places such as multiplex theatres, market areas, hospitals, function-halls, offices and shopping malls, one experiences the discomfort in looking out for a vacant parking slot, though it's a paid facility with an attendant/ security guard. The parking management system is proposed to demonstrate hazel free parking. The proposed system uses infrared transmitter-receiver pairs that remotely communicate the status of parking occupancy to the raspberry pi and displays the vacant slots on the display at the entrance of the parking so that 
the user gets to know the availability /unavailability of parking space prior to his/her entry into the parking place. Implementation involves minimal human interaction and provides a seamless parking experience thereby reducing a lot of time wasted by the user in parking his/her vehicle.

Limitation: If card is lost, It can be misused by some unknown person.

Karan Upendrabhai Vyas, Adarsh Kumar, Vadher Dhaval Hareshkumar [3] says that, this project is about an automatic underground car parking system for residents. The aim of this research is to develop \& implement an automatic parking system that will increase convenience \& security of residential parking system. The automatic parking system will be able to have less interaction of humans. The economy analysis technique will help in analyzing the project feasibility. Thus an efficient, reliable \& safe automatic underground parking system will increase availability of space for car parking. In metropolitan cities, vehicle parking has become a major concern in all busy areas and a good traffic system needs a good parking system. Different types of vehicle parking are applied worldwide namely Multilevel Automated Car Parking, Automated Car Parking System, Volkswagen Car Parking, etc. The present project work is aimed to develop a reduced working model of a car parking system for parking 6 to 24 cars within a parking area of $32.17 \mathrm{~m}^{2}$. The chain and sprocket mechanism is used for driving the parking platform. This model will be further useful for different branches of engineering in order to develop different types of automations like PLC, Micro controller and computerization etc. Limitation: This application is only used by malls which have underground parking system.

\section{METHODOLOGY}

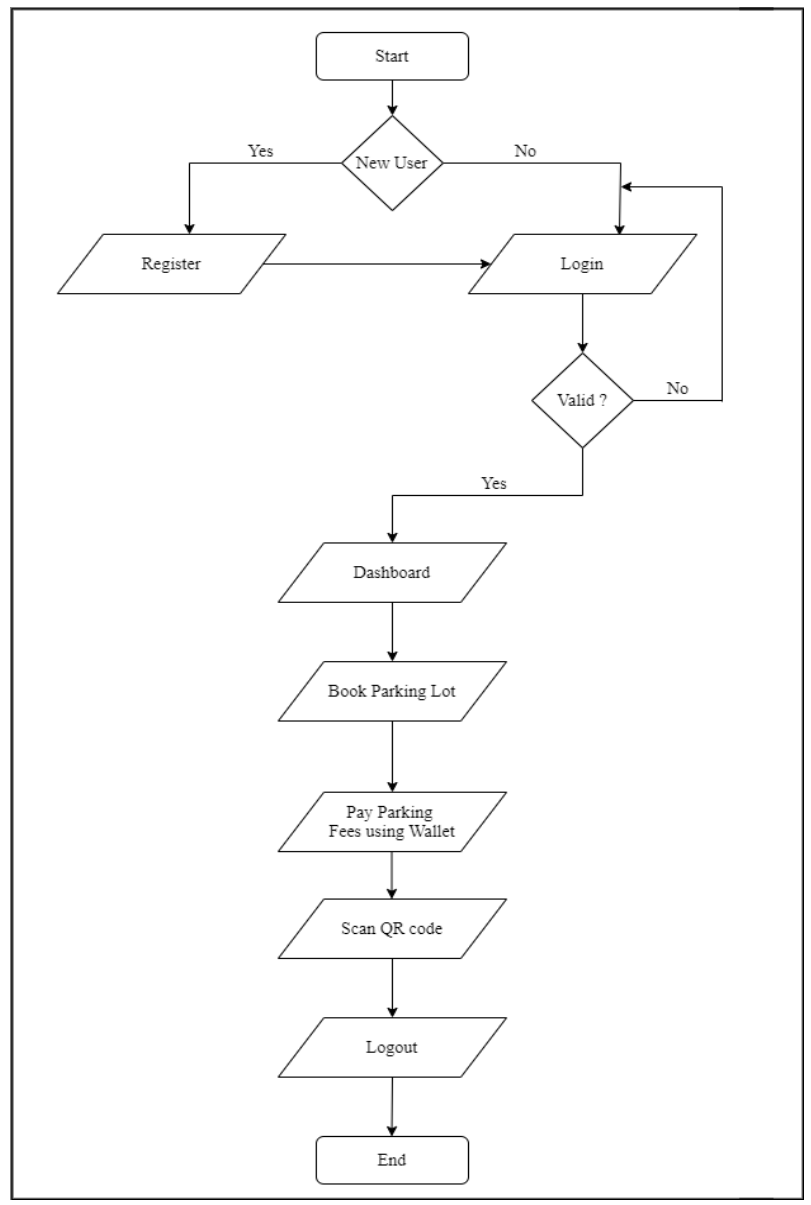

Description: The above diagram describes the system flow of our project, i.e, at the login page, if the user is authenticated, then it will move forward to the dashboard and if not authenticated, the user will be redirected to the login page.

After that at the dashboard parking lot will be booked at the desired location, online payment will be done through wallet, at the parking lot, the user will be authenticated through the generated QR code and after leaving the spot, the user can logout from the app.

\section{Circuit Diagram}

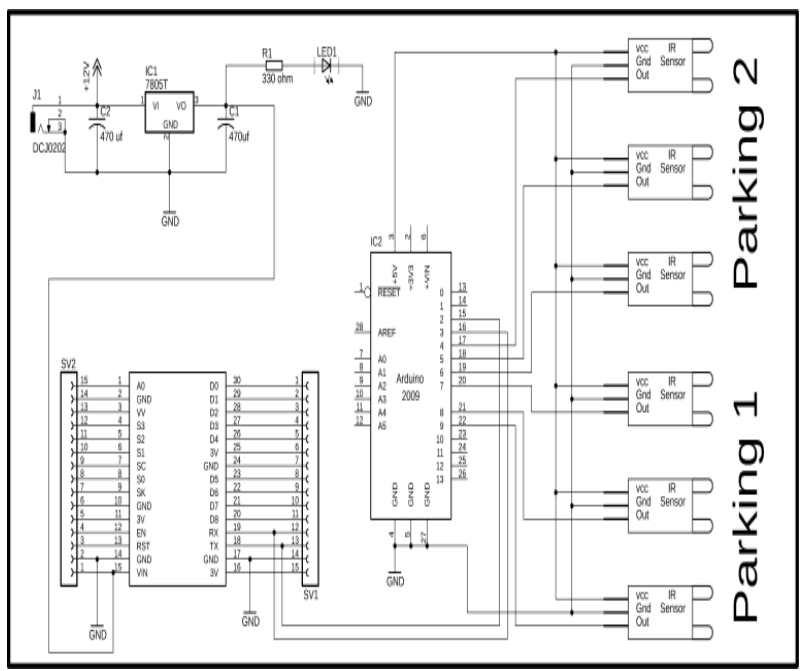

Description: As show in diagram six infrared sensors are connected with the Arduino pins 4 to 9 . The infrared sensor VCC pins are connected with the Arduino's 5v. Grounds are connected with the Arduino's Ground while the out pins of all the infrared sensors are connected with pin 4 to9. The Node mcu module tx and Rx pins are connected with pin 2 and pin 3 of the Arduino. while the Vin pin of the Node mcu module is connected with the output of the voltage regulator. This is a regulated $5 \mathrm{v}$ power supply based on the $\operatorname{lm} 7805$ voltage regulator. But you can also power up the Node mcu module using your laptop USB port. Two USB cables will be used, cable will be used for powering up the arduino and the other usb cable will be used to power up the node mcu.

IR Sensor: This is the IR sensor which will be using for the cars detection. As show in diagram the three male headers are clearly labeled with the VCC, GND, and OUT. The VCC pin is connected with the Arduino's 5 volts. The ground is connected with the Arduino's ground. While the OUT pin is connected with Arduino's IO pins. which will explain in the circuit diagram. While the black and white leds are the IR leds "one is the Tx while the other one is the Rx".

Nodemcu ESP8266: This is the Nodemcu ESP8266 wifi module, with the help of this module we can monitor the car parking slots from anywhere around the world. As you can see clearly all the pins are clearly labeled. Never power up the Nodemcu esp8266 wifi module using the Arduino's 5 volts. If you power up this module using the arduino's 5 volt then this wifi module we will keep reseting. To solve this problem you can design a separate power supply of this module using the LM7805 voltage regulator. 


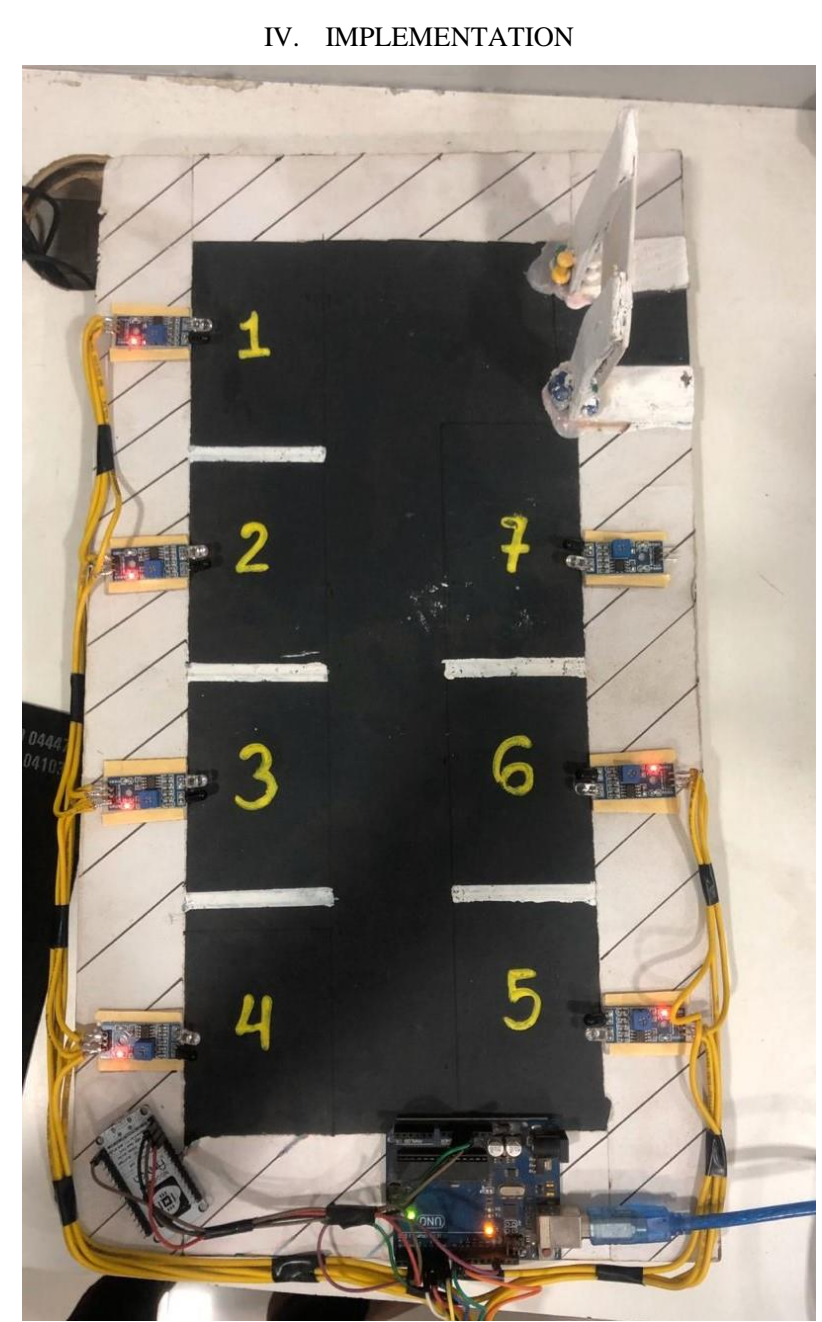

Description: The model of Smart Parking system has 6 parking lot and one entry and exit gate. For future maintenance, If any sensor doesn't work properly, an extra lot number 7 which is been kept disconnected. Each parking lot has a sensor which detects the object whenever any countable object passed around the range. All the sensors are connected with the Arduino Uno kit which supplies power. Arduino uno kit is connected with Node Mcu ESP 8266. ESP 8266 has instructions for sensors which has been imported from Arduino IDE. Arduino IDE is a software uesd for coding.

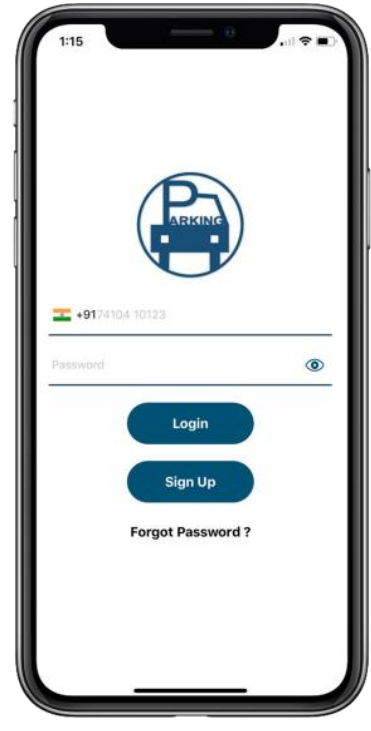

\section{Login Activity}

Description: Here the user will login with his/her registered mobile number and password.

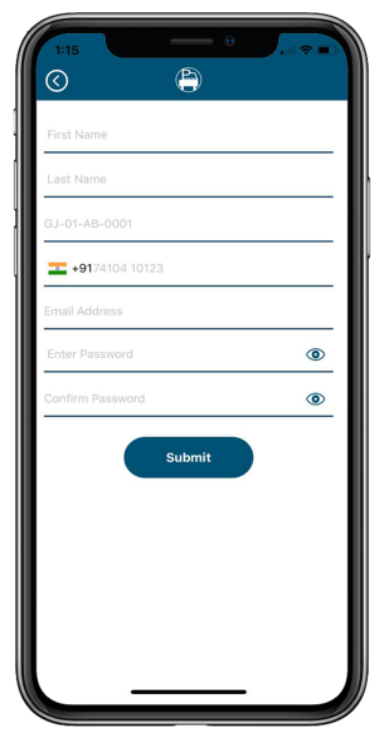

\section{Registration Activity}

Description: The vehicle user will register with his/her credentials. 


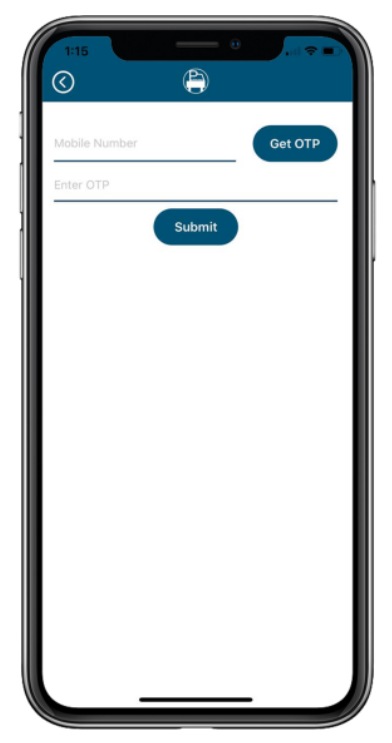

Authentication Activity

Description: In this activity, one time password will be sent to their registered mobile number to check whether the user is verified or not.

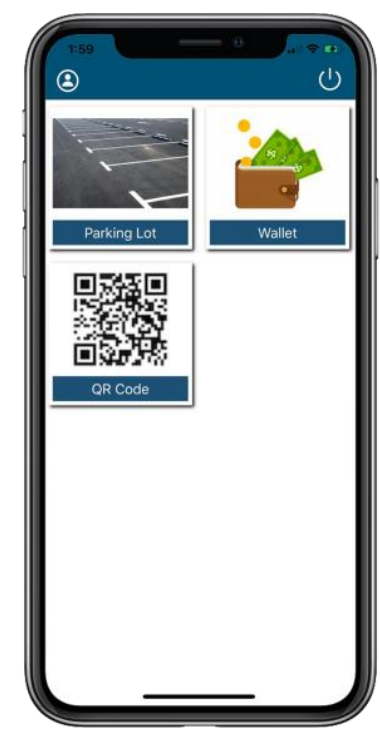

\section{Home Page Activity}

Description: Here the user can book parking lot according to his nearby area and pay money online by adding money in wallet and can generate QR code to verify themselves.

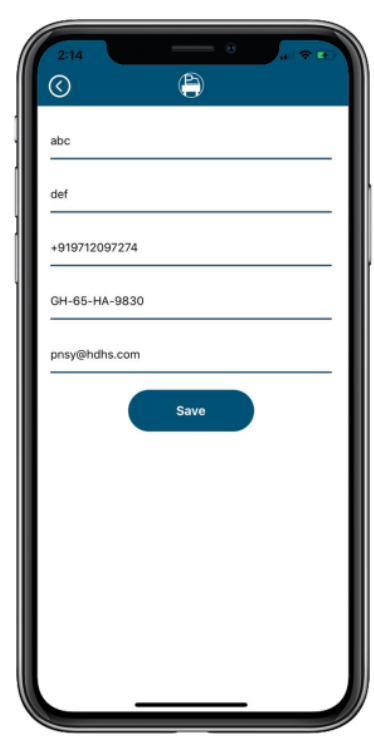

Edit Profile Activity

Description: In this activity, the vehicle user can edit and update their profile if they want to make any changes.

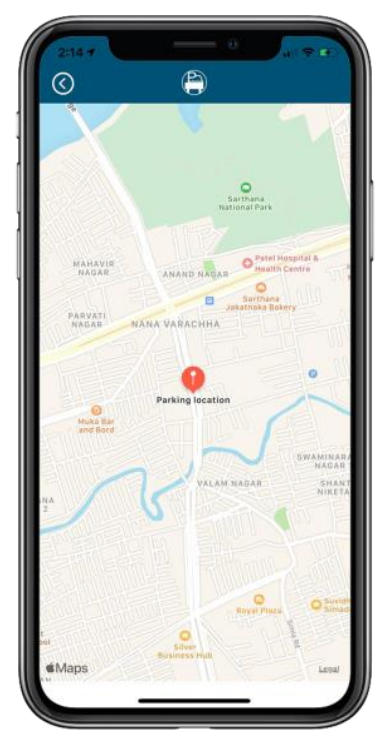

Map Activity

Description: In this mapping activity, the user can find parking lot according to his/her locality. 


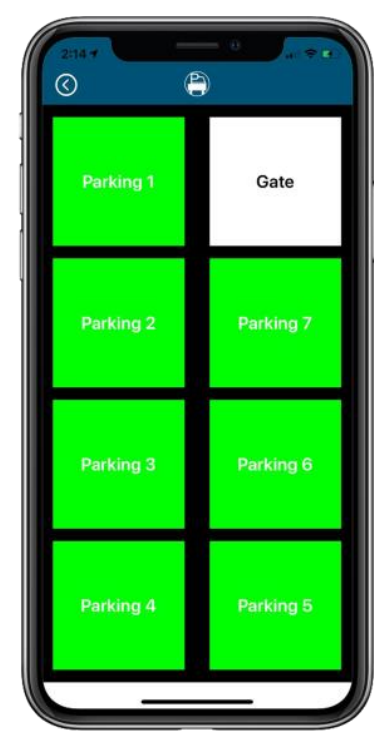

\section{Parking Lot Activity}

Description: Here the user will first check that the parking lot is reserved or not, if not than he/she will proceed for further booking details.

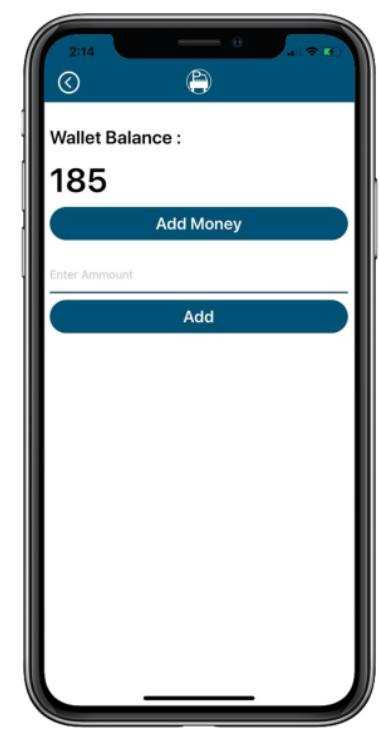

\section{Wallet Activity}

Description: Here the vehicle user adds money in wallet and pays for the parking fees according to his/her time duration.

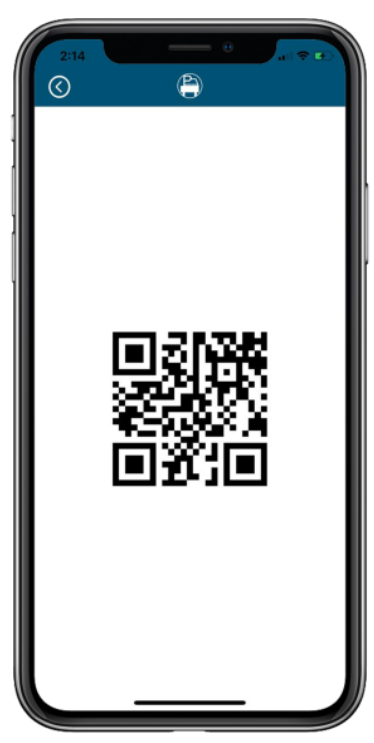

QR Code Activity

Description: In this activity the watchman of the parking lot will scan QR code generated by the vehicle user to verify that the user is authenticated or not.

\section{CONCLUSION \& FUTURE WORK}

The system's visual definition is to refrain from traffic and reduce time. This system will help you to find nearby parking lot in your area and you can book your parking lot. It also provides you online payment. So hereby, we conclude that with the implementation of the proposed system we will be able to reduce the time and traffic. We have proposed this system with its functional requirements.

\section{REFERENCES}

[1] "Smart parking system happiest minds" Aditya Basu, 2014 Happiest Minds https://www.happiestminds.com/Insights/smart-parking/

[2] "RFID based car parking system" Anusha, September 1, 2016 https://www.electronicshub.org/rfid-based-car-parking-system/

[3] "Automated underground car parking system" Karan Upendrabhai Vyas, Adarash Kumar, Vadher Dhaval Hareshkumar, December, 2014

http://library.atmiya.net:8080/dspace/bitstream/handle/123456789/2 593/AUTOMATIC\%20UNDERGROUND\%20CAR\%20PARKING $\%$ 20SYSTEM.pdf?sequence=1\&isAllowe $\mathrm{d}=\mathrm{y}$

[4] "Smart parking car ystem" Ali Abd Al-Zahra Jawad, Murtada Falah Hassan, Zain Hussam Muhsen, Mohammed Azher Therib(28/7/19) https://www.researchgate.net/publication/320356747_Design_and_I mplementation_of_Smart_Car_Parking_System 